\title{
Numerical investigations of flow and heat transfer enhancement in a semicircle zigzag corrugated channel using nanofluids
}

\author{
Raheem K. Ajeel ${ }^{1,2^{*}}$, Wan S. W. Salim ${ }^{1}$, Khalid Hasnan ${ }^{1}$ \\ ${ }^{1}$ Faculty of Mechanical and Manufacturing Engineering, Universiti Tun Hussein Onn Malaysia, 86400 Parit Raja, Batu \\ Pahat, Johor, Malaysia \\ ${ }^{2}$ Department of Mechanical Engineering, College of Engineering, University of Babylon, Babylon, Iraq
}

Corresponding Author Email: dashsin4@gmail.com

https://doi.org/10.18280/ijht.360418

Received: 5 June 2018

Accepted: 7 September 2018

\section{Keywords:}

heat transfer enhancement, turbulent

flow, semicircle-corrugated channel,

nanofluids, zigzag profile

\begin{abstract}
Thermal and hydraulic characteristics of turbulent nanofluid flow in a semicircle zigzag corrugated channel are numerically investigated by implementing the finite volume method (FVM) to describe the governing equations. Adiabatic condition for the straight walls, constant heat flux for the corrugated walls, and zigzag configuration of semicircle corrugated channel was examined. The performance of a semicircle zigzag corrugated channel with four types of nanofluids $\left(\mathrm{ZnO}, \mathrm{Al}_{2} \mathrm{O}_{3}, \mathrm{CuO}\right.$, and $\left.\mathrm{SiO}_{2}\right)$, with four various nanoparticle volume fractions of $2 \%, 4 \%, 6 \%$ and $8 \%$ using water as base fluid is thoroughly analyzed and discussed. The nanoparticles diameter, another parameter taken into consideration, varied from 20 to $80 \mathrm{~nm}$. Results show that the zigzag profile of semicircle corrugated channel has a great impact on the thermal performance compared with flat profile. The Nusselt number dropped as the nanoparticle diameter grew; however, it grew as the volume fraction of nanoparticles and Reynolds number increased. In addition, semicircle corrugated channel shows improvement in heat transfer of 1.5-2.7 times better than flat channel, with increase in the average Nusselt number of $170 \%$. The present investigation uncovers that these semicircle zigzag corrugated channels have favorable circumstances by utilizing nanofluids, which leads to promote the thermal performance of thermal devices and make it more compact.
\end{abstract}

\section{INTRODUCTION}

In recent years, many industries have a strong need to achieve higher thermal performance in order to gain high efficiency, reduce the cost and weight, and minimize the size of heat exchangers. In this context, the corrugated surface can be used as an alternative to the flat surface. One of the most important benefits for using corrugated channels includes reducing the thermal boundary layer thickness of the heat exchange surfaces. Therefore, the geometry of corrugated surface is considered as an efficient way to upgrade the heat transfer in these devices due to the appearance of the secondary flow regions in trough of corrugated channel which lead to improve the blending of the fluid medium and maximize the heat transfer exchange.

On the coolant side, the poor thermal properties of the conventional fluid are the main impediment for improving the efficiency of heat exchangers. In order to cope with these limitations, introduction of nanoparticles in a conventional fluid can be considered to jack up heat transfer abilities of these fluids. The component that produces (nanofluids) will have improved heat transfer capabilities, even with a small particle percentage. Many researchers have detected that the nanofluids are superior to the conventional fluids due to their efficient thermal performance [1-5]. For the purpose of examining the thermal performance of conventional fluids in corrugated channels, many studies have been conducted under various flow regimes.
To compare the thermal and hydraulic characteristics between a flat and corrugated channel, a numerical study was conducted under laminar condition by Fabbri [6]. The corrugated channel in this study consists of a smooth surface and a corrugated surface. The performance of heat transfer for the straight channel was $30 \%$ less than that in the corrugated channel while a $10 \%$ drop in pressure drop was observed, which the author attributed to the impact of Reynolds and Prandtl numbers.

Another numerical investigation about the thermal and hydraulic characteristics of the wavy channel was done by Bahaidarah et al. [7]. The investigation was carried out across 24 to 400 Reynolds numbers and Prandtl number was 0.7 . The study was carried out by using the sinusoidal and arcshaped as a geometric parameter. Both channel configurations showed that the increase in Re leads to increase $\mathrm{Nu}$. Also, arc-shaped channel was highest in the $\Delta \mathrm{p}$ compared to the sinusoidal channel. Amiri [8] numerically studied the fluid flow in the branched channels. Two types of Y-shaped channel were used, which ones named as a straight Y-shaped channel and a diagonal Y-shaped channel. Computational experiments based on the Response Surface Methodology were used to predict the proposed model. Results showed that with increasing the angle and decreasing the Reynolds number, Recirculation length decreases. Naphon [9-11] conducted numerically and experimentally the forced convective flow in corrugated channels. The computational model was simulated by the commercial CFD 
program and the k- $\varepsilon$ model. The outcomes proved that the corrugated surface had an efficient impact on heat transfer enhancement. The impacts of the entrance region in terms of heat transfer enhancement and flow behavior through a symmetric wavy-channel was numerically conducted by Mohamed et al. [12]. The amplitude of the surface was range of 0-0.5, while Reynolds number ranged between 100-1500. They indicated that the $\mathrm{Nu}$ and the shear stress rise by increasing the $\mathrm{Re}$ and highest values appearing in the entrance zone.

Elshafei et al. [13] examined the turbulent flow characteristics and heat transfer through corrugated channels experimentally. The study utilized constant temperature condition over $\mathrm{Re}$ range of 3220-9420. The geometrical configurations were varied by changing the channel spacing and the alignment of the opposing corrugated surfaces (phase shifts). The outcomes proved that the heat transfer enhancement was greatly affected by using the corrugated surface. For the same purpose, Islamoglu and Parmaksizoglu [14] conducted an experimental work in order to examine the influence of corrugated channel height in terms of heat transfer enhancement and air flow behavior through a triangular corrugated channel. Over a Reynolds number range of 1200-4000 with air as working fluid, the HTC and $f$ were evaluated for channel heights of 5 and $10 \mathrm{~mm}$ with the angle of the corrugation maintained at $20^{\circ}$. The results show that the corrugated channel has great impact on HTC and $f$ and the increase in height of channel led to rise in the $\mathrm{Nu}$ and the $f$. Experimentally, Ali and Ramadhyani [15] performed their investigation to study enhancement of heat transfer through corrugated channels. For both corrugated channels, the experimental study showed that the performance evaluation is superior to the straight channel under design constraints. Hong et al. [16] studied numerically the gas flow at different temperatures, $373 \mathrm{~K}, 323 \mathrm{~K}$, and $273 \mathrm{~K}$ in microchannel having straight rectangular cross-section. They employed the direct simulation Monte Carlo to simulate and compare between 3 and 2-D cases. The results indicated that the additional side-walls for the 3-D cases have great impact on the heat transfer and flow properties compared to the 2-D cases. By implementing the (FVM) and k- $\varepsilon$ turbulence model, the turbulent flow of air in cross corrugated plate of corrugation profile at low Reynolds number has been numerically examined by Zhang and Che [17]. The study tested different types of corrugation profile such as trapezoidal, isosceles triangular, elliptic, rectangular and sinusoidal and their effect on thermal and hydraulic characteristics of flow. The outcomes proved that the heat transfer enhancement was greatly affected by using the corrugated surface where the trapezoidal channel was superior to the elliptic channel by approximately 4 times. Asako et al. [18] examined the heat transfer and pressure drop through a corrugated duct having rounded corners numerically. The parameters adopted in this investigate include three assigned corrugation angles $\left(15^{\circ}, 30^{\circ}\right.$, and $\left.45^{\circ}\right)$, $\operatorname{Pr}=0.7$ and $\operatorname{Re}=100-1000$. Under identical mass flow rate and pumping power, they indicated that the corrugated duct with round corners has a great impact compared to the plain duct in terms of heat transfer progress.

On the other hand, many researchers have given more attention to study the convective heat transfer of nanofluids in straight channels numerically and experimentally. Mohammed et al. [19] numerically tested the effects of different nanofluids $\left(\mathrm{Al}_{2} \mathrm{O}_{3}, \mathrm{TiO}_{2}, \mathrm{SiO}_{2}\right.$ and $\mathrm{Ag}$-water $)$ on the thermal and hydraulic characteristics at Reynolds number from 100 to 800 . Water and nanoparticles with concentrations of $2 \%, 5 \%$ and $10 \%$ were used in the simulation and (FVM) employed to deal with the governing equations. The results obtained exhibited an increase of the thermal performance in a microchannel due to the influence of using nanofluid as a base fluid. Abu-Nada [20] conducted another numerical study in terms of heat transfer over a backward facing step by implementing various kinds of nanofluids. The investigation was carried out across 200 to 600 Reynolds number while the nanoparticles $\phi$ was $0-0.02$. They reported that $\mathrm{Nu}$ increased with an increased in $\phi$ of nanoparticles and Re. In addition, within recirculation regions, $\mathrm{TiO}_{2}$ having low thermal conductivity leads to further improvement on heat transfer. Laminar flow of $\mathrm{Cu}$ /water nanofluid in rectangular duct at Re of 5-1500 has been numerically studied by Santra et al. [21]. The said study revealed that the increase in $\phi$ as well as the flow rate will produce a greater heat transfer rate. Kalteh et al. [22] examined the $\mathrm{Cu}$-water nanofluid effects on the thermal and hydraulic characteristics for a 2-D laminar forced convection flow inside microchannel numerically. They reported that the heat transfer enhancement was greatly affected by using the nanofluid where his rating increased with the increase in $\mathrm{Re}$ and $\phi$, whereas the $\Delta p$ increases only slightly.

Recently, Ajeel and Salim [23] examined the impact of nanofluid with aluminum oxide nanoparticles on the heat transfer and $f$ in semi-circular corrugated channel numerically. Symmetry configuration for corrugation profile of semicircle has been employed. They reported from the obtained results that adopted geometry of semicircle corrugated profile with nanofluid can contribute to promote the performance of heat transfer devices. In addition, the outcomes of study showed that the increased ratio in Nusselt number was 2.07 at $\mathrm{Re}=30000$ and volume fraction $6 \%$. Abed et al. [24] examined the impacts of nanofluid as a heat transfer fluid on thermal and hydraulic characteristics in a 2$\mathrm{D}$ corrugated plate having $\mathrm{v}$-shaped numerically. Under uniform heat flux over a range of Re (8000-20000) with copper oxide, zinc oxide, silicon dioxide and aluminum oxide, the study was tested. They reported from the obtained results that adopted geometry of $\mathrm{v}$-shaped with nanofluid can contribute to improving the efficiency of heat transfer devices and make them more compact, which can be inferred from the enhanced Nusselt number results. Ahmed et al. [25] investigated the influence of various types of nanofluid on thermal and hydraulic characteristics through triangular corrugated channels numerically. Under 2-D turbulent condition over a range of $\operatorname{Re}(8000-20000)$ with copper oxide, zinc oxide, silicon dioxide and aluminum oxide nanoparticles, the study was tested. The results revealed the extent to which the effects of triangular corrugated channel and nanofluid on enhancement the thermal - hydraulic performance.

Depending on the mentioned literature, it can be inferred that the forced convective heat transfer in a semicircle zigzag - corrugated channel using nanofluids seems not to have been investigated numerically in the past. In addition, most of the previous studies examined a $2 \mathrm{D}$ turbulent convective heat transfer. Accordingly, this lack of knowledge represents the prime motivation behind conducting the current research. Thus, the current study examines turbulent forced convective flow in three-dimensional semicircle-corrugated channels over Reynolds numbers in the range of $10,000 \leq \operatorname{Re} \leq 30,000$ under constant heat flux condition and using four kinds of 
nanofluids. Results of interest including average Nusselt number $\left(\mathrm{Nu}_{\mathrm{av}}\right)$, pressure drop $(\Delta \mathrm{p})$, Nusselt number enhancement ratio $\left(\mathrm{Nu}_{\mathrm{er}}\right)$, and thermal performance factor (PEC) for turbulent forced convective of nanofluids in a semicircle zigzag -corrugated channel are reported to show the effect of semicircle corrugated channel and nanofluid on these parameters.

\section{GEOMETRICAL MODEL}

The 2-dimensional geometry of the semicircle zigzag corrugated channel is illustrated in Figure 1. The details of Figure 1 are given as (a) which represents the Geometrical model, (b) represents the semicircle zigzag - corrugated channel, and (c) computational mesh domain.

Generally, the corrugations are placed at the top and bottom walls and the sides of the channel are maintained flat. The flow domain is comprised of three parts; the test section with the corrugations which are heated from the upper and lower surfaces, downstream and upstream sections, with smooth, flat surfaces, which are treated as adiabatic surfaces. The overall length of the channel is $700 \mathrm{~mm}$ with the upstream, entrance section with length of $400 \mathrm{~mm}$, the test section (corrugated wall $=200 \mathrm{~mm}$ ) and the exit section with length of $100 \mathrm{~mm}$. The entrance section is provided to enclose fully developed flow entering the corrugated section while the downstream section (exit section) is provided to prevent reverse flow from affecting the results. The height of channel (H) is $10 \mathrm{~mm}$ while the width is $(\mathrm{W}=5 H)$. The pitch of corrugation is $(p=1.5 \mathrm{H})$ while the width and height of corrugation are $(\mathrm{w}=\mathrm{H} / 2),(\mathrm{h}=\mathrm{H} / 4)$, respectively.

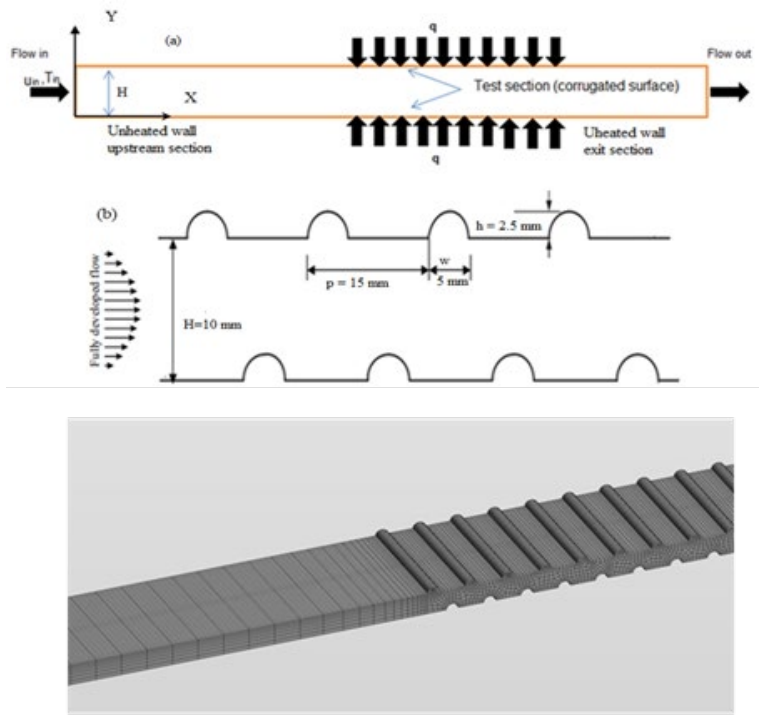

Figure 1. Schematic diagram of corrugated channel, (a) geometrical model, (b) semicircle zigzag-corrugated channel, and (c) computational mesh domain

\subsection{Assumptions and governing equations}

The governing equations are solved for three-dimensional flow and temperature fields with several assumptions: (i) The flow is steady; (ii) The working fluid mixture is uniform and is incompressible without phase-change; (iii) Constant heat flux condition is considered and the slip was neglected (iv) The Reynolds number is sufficiently high to induce turbulence. This type of flow is represented by the following governing equations [26].

Continuity equation:

$\frac{\partial U_{i}}{\partial X_{i}}=0$

Momentum equation:

$\frac{\partial\left(U_{i} U_{j}\right)}{\partial X_{j}}=-\frac{\partial p}{\partial X_{i}}+\frac{\partial}{\partial X_{j}}\left(\mu \frac{\partial U_{i}}{\partial X_{j}}-\overline{\rho u_{i} u_{j}}\right)$

Energy equation:

$\frac{\partial\left(U_{i} U_{j}\right)}{\partial X_{j}}=-\frac{\partial}{\partial X_{i}}\left(\frac{\mu}{\operatorname{Pr}} \frac{\partial T_{i}}{\partial X_{j}}-\overline{\rho u_{i} t_{j}}\right)$

The Reynolds stresses in momentum equation and heat fluxes in energy equation are, respectively, shown below:

$\left.\overline{\rho u_{i} u_{j}}=-\mu_{t}\left(\frac{\partial U_{i}}{X_{j}}+\frac{\partial U_{j}}{X_{i}}\right)+\frac{2}{3} \delta_{i j} k\right]$

$\overline{\rho u_{i} t_{j}}=-\frac{\mu_{t}}{\sigma_{\theta}} \frac{\partial T_{i}}{\partial X_{j}}$

The corresponding transport equations in the standard k- $\varepsilon$ model, which are turbulence kinetic energy and energy dissipation [27], is given as:

$\frac{\partial \rho k U_{i}}{\partial X_{j}}=-\frac{\partial}{\partial X_{j}}\left[\left(\mu+\frac{\mu_{t}}{\sigma_{k}}\right) \frac{\partial k}{\partial X_{j}}\right]+\rho\left(G_{b}-\varepsilon\right)$

$\frac{\partial \rho \varepsilon U_{i}}{\partial X_{j}}=-\frac{\partial}{\partial X_{j}}\left[\left(\mu+\frac{\mu_{t}}{\sigma_{k}}\right) \frac{\partial \varepsilon}{\partial X_{j}}\right]+\rho \frac{\varepsilon}{k}\left(c_{1 \varepsilon} G_{b}-c_{2 \varepsilon} \varepsilon\right)$

$G_{b}=\mu_{t}\left(\frac{\partial u_{i}}{\partial X_{j}}+\frac{\partial u_{j}}{\partial X_{i}}\right) \frac{\partial u_{i}}{\partial X_{j}}$

$\mu_{t}=\rho c_{\mu} \frac{k^{2}}{\varepsilon}$

where:

$C_{1 \varepsilon}=1.44, C_{2 \varepsilon}=1.92, C_{\mu}=0.09, \sigma_{k}=1.0, \sigma_{\varepsilon}=1.3$.

In order to present the results of numerical solution, some useful parameters can be obtained. The Nuav can be defined as below:

$\overline{\mathrm{Nu}}=\frac{\bar{h} D_{h}}{k_{\mathrm{f}}}$

The average heat transfer coefficient as:

$\bar{h}=q^{\prime \prime} \cdot \frac{\ln \left(\frac{T_{w}-T_{f, \text { in }}}{T_{w}-T_{f, \text { out }}}\right)}{\left(\mathrm{T}_{\mathrm{w}}-\mathrm{T}_{\mathrm{f}, \text { in }}\right)-\left(\mathrm{T}_{w}-\mathrm{T}_{\mathrm{f}, \text { out }}\right)}$

$\mathrm{q}^{\prime \prime}=\dot{\mathrm{m}} C_{p}\left(T_{f, \text { in }}-T_{f, \text { out }}\right) / A$

where $T_{f, \text { in }}, T_{f, \text { out }}$ are the average inlet and outlet temperatures of the working fluid while $\mathrm{A}$ is the corrugated surface area.

Additionally, the inlet velocity can be obtained based on the required Reynolds number as below: 
$u_{i n}=\frac{\mathrm{R}_{\mathrm{e}} \mu}{\rho D_{h}}$

In the corrugated semicircle zigzag channel, the hydraulic diameter is computed based on cross section area (Across) and the perimeter of wetted $(\mathrm{P})$ as [28]:

$\mathrm{D}_{\mathrm{h}}=\frac{4 \mathrm{~A}_{\text {cross }}}{P}$

The Fanning friction factor as:

$C_{f x}=\frac{2 \tau_{s}}{\rho \mathrm{u}_{\text {in }}^{2}}$

The friction factor is defined [28, 29]:

$f=4 C_{f x}$

The pressure drop can also be obtained as [28, 29]:

$\Delta p=f \frac{\rho L_{c o r r} \mathrm{u}_{i n}^{2}}{2 D_{h}}$

For a better evaluation system, the performance evaluation criterion (PEC) was computed to investigate the thermal performance of the corrugated channel (based on the ratio between the heat transfer enhancements into the increase in friction factor). The thermal performance factor is given by [30]:

$P E C=\frac{\left(\overline{N u} / \overline{N u_{0}}\right)}{\left(f / f_{0}\right) 1 / 3}$

\subsection{Boundary conditions}

Computational domains and boundary conditions were applied at the semicircle zigzag- corrugated channel which included velocity inlet condition and temperature of $300^{\circ} \mathrm{C}$, pressure outlet condition while slip velocity was ignored. Additionally, there was uniform heat flux on the corrugated walls $\left(\mathrm{q}=10 \mathrm{kw} / \mathrm{m}^{2}\right)$ whereas adiabatic condition is applied on the remaining straight walls. The specific thermal conditions for the complex flow and the boundary conditions can be illustrated as below:

i. At the inlet:

$u=u_{\text {in }}, v=w=0, T_{\text {in }}=300 K, k=k_{\text {in }}, \varepsilon=\varepsilon_{\text {in }}$

ii. Outlet boundary: In current study, fully developed for the properties are assumed at the outlet.

$\frac{\partial T_{f}}{\partial x}=0, \frac{\partial u}{\partial x}=\frac{\partial v}{\partial x}=\frac{\partial w}{\partial x}=0$, and $\frac{\partial k}{\partial x}=\frac{\partial \varepsilon}{\partial x}=0$

iii. At the wall:

$u=v=w=0, q=q_{\text {wall }}$

At the inlet, the turbulent kinetic energy $\left(\mathrm{k}_{\mathrm{in}}\right)$ and the turbulent dissipation $\left(\varepsilon_{\mathrm{in}}\right)$ are approximated from the turbulent intensity I as follows [28] :

$k_{\text {in }}=\frac{3}{2}\left(u_{\text {in }} I\right)^{2}$ $\varepsilon_{\text {in }}=C_{\mu} 3 / 4 \frac{k^{3 / 2}}{L}$

where the turbulent intensity (I) is [28]:

$I=\frac{\dot{u}}{u} \times 100 \%$

\section{NUMERICAL IMPLEMENTATION AND GRID INDEPENDECE TEST}

A numerical simulation for a semicircle zigzag corrugated channel was performed by employing nanofluid in order to probe the characteristics of heat transfer and flow fluid. The finite volume method is used to solve the governing equations with corresponding boundary conditions by employing the CFD commercial software ANSYSFLUENT-V16.1. The SIMPLE algorithm is employed to joint of the pressure-velocity system and a $2^{\text {nd }}$ order upwind scheme was also utilized for the convective terms. The k- $\varepsilon$ turbulent model is selected while the diffusion term in the momentum and energy equations is approximated by $2^{\text {nd }}$ order upwind. By $10^{-5}$ of residues for continuity, momentum and turbulence equations and by $10^{-10}$ for energy equation, the solutions are considered converged.

For the purpose of providing a measure of reliability and accuracy of the numerical results, five values of grid size of $2.5,2,1.5,1.0$ and 0.9 were examined. Therefore, the local $\mathrm{Nu}$ and local skin friction coefficient for water flow at the lower corrugated wall of the semicircle zigzag corrugated channel are computed at $\mathrm{Re}=10000$ and various grid size as shown in Figure 2. Furthermore, the sizes of grid are tested to check the effect of the grid density on the computational results in terms of average Nusselt number as shown in Table 1. It is detected that the grid size of 413520 can achieve and confirm grid independence solution.
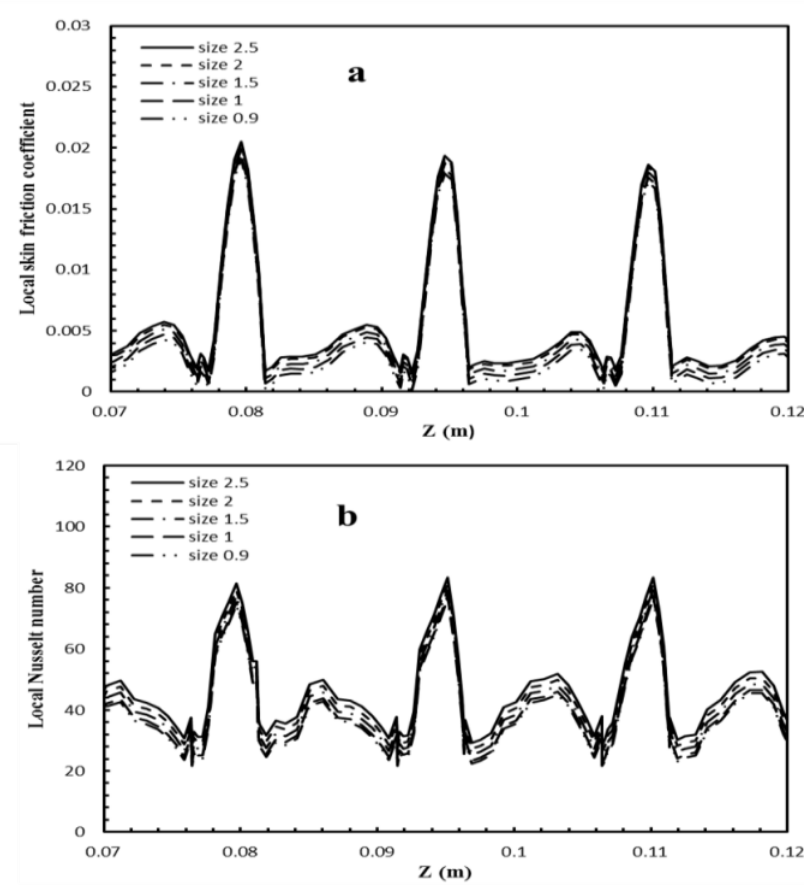

Figure 2. Grid independence test (a) local skin friction coefficient, and (b) local Nusselt number 
Table 1. Grid independence test

\begin{tabular}{ccc}
\hline Grid number & Average Nusselt number & Relative error $\%$ \\
\hline 162632 & 126.1311 & - \\
267696 & 126.1546 & 0.018628 \\
329668 & 126.1789 & 0.019258 \\
413520 & 126.1896 & 0.008479 \\
544235 & 126.1971 & 0.005943 \\
\hline
\end{tabular}

\section{THERMOPHYSICAL NANOFLUIDS}

PROPERTIES

OF

To execute the simulations, the effective thermophysical properties of nanofluids should be obtained. In this regard, four kinds of nanopowder, namely, $\mathrm{Al}_{2} \mathrm{O}_{3}, \mathrm{CuO}, \mathrm{SiO}_{2}$ and $\mathrm{ZnO}$, were utilized and by applying the mixing theory, the required properties for simulations can be obtained as explained below:

The density [31]:

$\rho_{n f}=(1-\phi)+\phi \rho_{n p}$

The effective heat capacity [31]:

$\left(\rho C_{P}\right)_{n f}=(1-\phi)\left(\rho C_{P}\right)_{f}+\phi\left(\rho C_{P}\right)_{n p}$

In order to compute the $\left(\mathrm{k}_{\mathrm{eff}}\right)$ by using nanoparticles in corrugated channel, the effect of Brownian motion will be taken into consideration by utilizing the empirical correlation below [32] :

$k_{\text {eff }}=k_{\text {static }}+k_{\text {Brownian }}$

$k_{\text {static }}=k_{f}\left[\frac{\left(k_{n p}+2 k_{f}\right)-2 \phi\left(k_{f}-k_{n p}\right)}{\left(k_{n p}+2 k_{f}\right)+\phi\left(k_{f}-k_{n p}\right)}\right]$

$k_{\text {Brownian }}=5 * 10^{4} \beta \phi \rho_{f} C_{p, f} \sqrt{\frac{K T}{2}} f(T, \phi)$

where:

Boltzmann constant: $\mathrm{k}=1.3807 * 10-23 \mathrm{~J} / \mathrm{k}$ and Table 2 shows the values of $\beta$ used in the current study.

Modeling $f(T, \phi)$ :

$f(T, \phi)=\left(2.8217 \times 10^{-2} \phi+3.917 \times 10^{-3}\right)\left(\frac{T}{T_{0}}\right)+$ $\left(-3.0669 \times 10^{-2} \phi-3.391123 \times 10^{-3}\right)$

Another property of nanofluid is effective viscosity [33]:

$\mu_{e f f=\mu_{f}} *\left(\frac{1 * \phi^{-1.03}}{1-34.87\left(\frac{d_{p}}{d_{f}}\right)^{-0.3}}\right)$

Equivalent diameter of based molecule:

$d_{f}=\left[\frac{6 M}{N \pi \rho_{f 0}}\right]^{1 / 3}$

Table 3 illustrates the thermo-physical properties of nanofluids with $d_{p}=20 \mathrm{~nm}$ and $\phi=0.02$.

\section{CODE VALIDATION}

For the goal of gaining a better comprehension of the competences, restrictions and validated numerical codes with other previous work, code validation is quite essential procedure in any numerical work. Likewise, lower error values mean higher accuracy of the simulation and preparedness for numerical runs.

First, the outcomes of the present study for straight channel in terms of Nusselt number and friction factor are compared with the empirical correlations of Gnielinski [34] and Petukov [35], respectively, as displayed in Figure 3a-b. Depending on the Reynolds number values and the empirical correlations, the calculating time does not exceed one hour to get the results.

$N u_{a v}=\frac{(f / 8)(R e-1000) P r}{1+12.7(f / 8)^{0.5}\left(\operatorname{Pr}^{2} / 3-1\right)}$

$f=(0.79 \ln (R e)-1.64)^{-2}$

Another code validation, one which depended on the experimental work of Elshafei et al. [13] for turbulent air flow in straight and corrugated channels, was also carried out. The outcomes of comparison display a good agreement in regard to the $N u_{a v}$ as shown in Figure. $3 \mathrm{c}$.
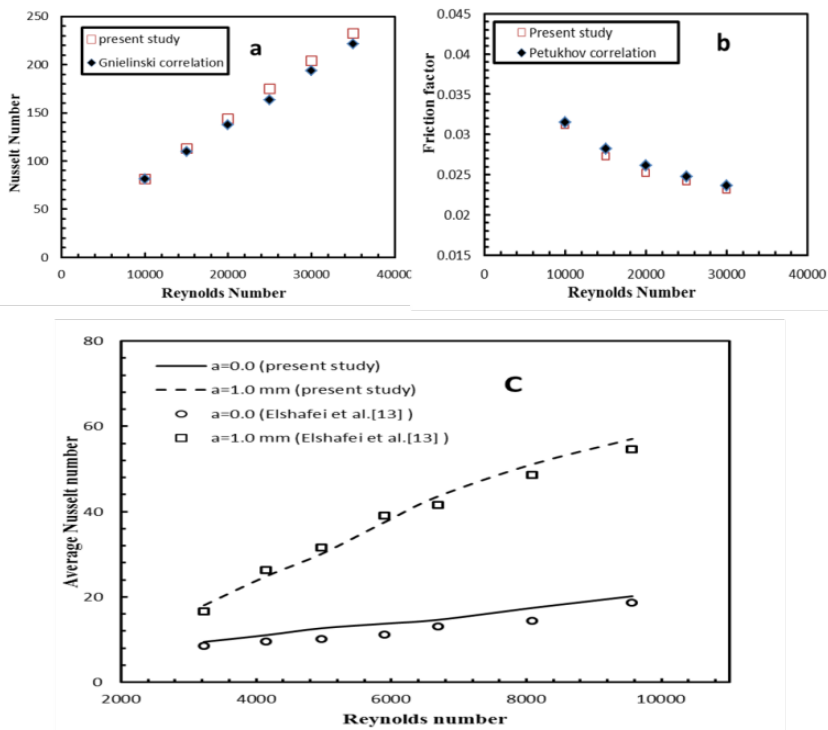

Figure 3. Average Nusselt number (a) and friction factor (b) vs. Reynolds number, and comparison between the current work and the outcomes of (c) Elshafei et al. [13]

\section{RESELUTS AND DISCUSSION}

The influences of utilizing semicircle corrugated channel with zigzag configuration, types of nanofluid, diameter and volume fraction of the particles, Reynolds number on the thermal and hydraulic characteristics as well as flow fields in terms of the $\mathrm{Nu}_{\mathrm{av}}, \mathrm{Nu}_{\mathrm{er}}, \Delta \mathrm{p}$ and PEC have been reported and debated in this section. 
Table 2. Values of $\beta$ for different nanoparticles

\begin{tabular}{|c|c|c|c|}
\hline$\phi$ & $\beta$ & $\begin{array}{c}\text { Concentration } \\
(\%)\end{array}$ & Temperature(K) \\
\hline $\mathrm{Al}_{2} \mathrm{O}_{3}$ & $\begin{array}{c}8.4407(100 \phi)^{-} \\
1.07304\end{array}$ & $\begin{array}{c}1 \% \leq \varphi \leq \\
10 \%\end{array}$ & $\begin{array}{c}298 \mathrm{~K} \leq \mathrm{T} \leq \\
363 \mathrm{~K}\end{array}$ \\
\hline $\mathrm{CuO}$ & $\begin{array}{c}9.881(100 \phi)^{-} \\
0.9446\end{array}$ & $1 \% \leq \varphi \leq 6 \%$ & $\begin{array}{c}298 \mathrm{~K} \leq \mathrm{T} \leq \\
363 \mathrm{~K}\end{array}$ \\
\hline $\mathrm{SiO}_{2}$ & $\underset{1.4594}{1.9526(100 \phi)^{-}}$ & $\begin{array}{c}1 \% \leq \varphi \leq \\
10 \%\end{array}$ & $\begin{array}{c}298 \mathrm{~K} \leq \mathrm{T} \leq \\
363 \mathrm{~K}\end{array}$ \\
\hline $\mathrm{ZnO}$ & $\begin{array}{c}8.4407(100 \phi)^{-} \\
1.07304\end{array}$ & $1 \% \leq \varphi \leq 7 \%$ & $\begin{array}{c}298 \mathrm{~K} \leq \mathrm{T} \leq \\
363 \mathrm{~K}\end{array}$ \\
\hline
\end{tabular}

Table 3. Thermo-physical properties of nanofluids with $d_{p}=$ $20 \mathrm{~nm}$ and $\phi=0.02$

\begin{tabular}{ccccc}
\hline $\begin{array}{c}\text { Thermo- } \\
\text { physical } \\
\text { properties }\end{array}$ & $\mathrm{Al}_{2} \mathrm{O}_{3}$ & $\mathrm{SiO}_{2}$ & $\mathrm{CuO}$ & $\mathrm{ZnO}$ \\
\hline $\begin{array}{c}\text { Density } \rho \\
\left(\mathrm{kg} / \mathrm{m}^{3}\right)\end{array}$ & 1050.24 & 1022.24 & 1108.24 & 1090.24 \\
$\begin{array}{c}\text { Dynamic } \\
\text { viscosity, } \\
\mu\left(\mathrm{Ns} / \mathrm{m}^{2}\right)\end{array}$ & 0.0012377 & 0.0012377 & 0.0012377 & 0.0012377 \\
$\begin{array}{c}\text { Thermal } \\
\text { onductivity, } \\
\mathrm{k}(\mathrm{w} / \mathrm{m} . \mathrm{K}) \\
\begin{array}{c}\text { Specific } \\
\text { heat, } \mathrm{c}\end{array}\end{array}$ & 0.685 & 0.620 & 0.682 & 0.672 \\
$(\mathrm{~J} / \mathrm{kg} . \mathrm{K})$ & 3947.74 & 4032.25 & 3754.26 & 3803.26 \\
\hline
\end{tabular}

\subsection{Nanoparticles type effect}

Figure. 4 illustrates the velocity and isotherm contours for base fluid and nanofluid flow at nanoparticle diameter of 20 $\mathrm{nm}, \phi=8 \%$ and $\mathrm{Re}=30000$ for the various kinds of nanoparticles. The velocity contours display that the most striking finding was the firmer converse flow zones in the state of silicon dioxide - water nanofluid followed by aluminum oxide, zinc oxide, and copper oxide /water nanofluid and lastly pure water. According to inverse proportionality between density and velocity, the low density of $\mathrm{SiO}_{2}$-water plays a significant role to jack up the velocity rate at the same Re. Therefore, the nanofluid, silicon dioxide-water, has a highest velocity among the other nanofluids that effects to increase the recirculation zones.

On the other hand, the isotherm contours demonstrate the thermal boundary layer thickness for all types of nanofluid. Due to the high values of Prandtl number for $\mathrm{SiO}_{2}$-water nanofluids, the thermal boundary layer thickness in this case is not as much as that for other nanofluids. In addition, the better refinement in the fluid blending in the case of silicon dioxide - water nanofluid is due to the intensity of converse flow regions. This makes nanofluid with silicon dioxide the highest augmentation in terms of heat transfer among other types of nanofluids.

Figure. $5 \mathrm{~A}$ shows the outcomes of the $\mathrm{Nu}_{\mathrm{av}}$ which are obtained from the simulation of the different nanofluids kinds compared with using pure water as a heat transfer fluid in zigzag configuration of semicircle corrugated channel. The outcomes show that every one of the nanofluids gives larger $\mathrm{Nu}_{\mathrm{av}}$ values than pure water. Clearly, the pure water has lowest $\mathrm{Nu}_{\mathrm{av}}$ because of poor thermal conductivity of this fluid, whereas the nanofluid with $\mathrm{SiO}_{2}$ nanoparticles has the highest ratings of $\mathrm{Nu}_{\mathrm{av}}$. As a result, the nanofluid with $\mathrm{SiO}_{2}$ nanoparticles is followed by nanofluid with particles of aluminum oxide, zinc oxide, and copper oxide, respectively. High velocity is a major reason for this rise due to the effect of the lowest density which correlates to the increase of the HTC. What is more, the intensity effect of the converse regions is also very important to achieve the trouble that stems from increase in the velocity of $\mathrm{SiO}_{2}$-water nanofluid. The outcomes are in agreement with results of Mohammed et al. [1].

The pressure drop against $\mathrm{Re}$ with nanofluids types is displayed in Figure 5 (B). It is worth noting that the pure water has a lower rate of pressure drop than pressure drop in all types of nanofluids. One possible reason is the effect of lower density and viscosity of base fluid compared to nanofluid. Similarly, the high velocity makes silicon dioxide - water nanofluid superior to the other types of nanofluid in terms of pressure drop due to increase in the shear stress nearby corrugated walls.

(a)
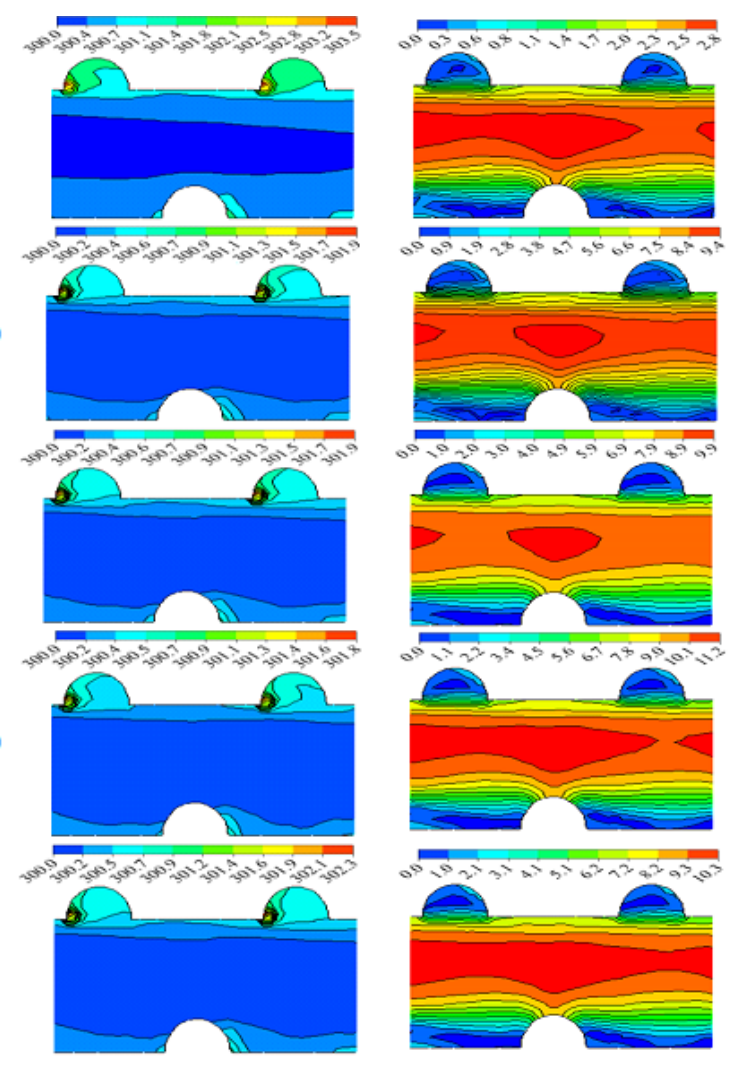

Figure 4. Streamlines (right) and isotherms (left) contours for different types of nonofluids and pure water at $\mathrm{Re}=30000$ : (a) water, (b) $\mathrm{CuO}$-water, (c) $\mathrm{ZnO}$-water, (d) $\mathrm{Al}_{2} \mathrm{O}_{3}$-water, and (e) $\mathrm{SiO}_{2}$-water

Figure 5(C) demonstrates the ratio of the $\mathrm{Nu}_{\mathrm{av}}$ of semicircle zigzag- corrugated channel with various types of nanofluids to that of the base fluid flow in flat channel. Although there was a fall in tandem with increases in Reynolds number in the enhancement ratio for each kind of fluid, the nanofluids type recorded the highest enhancement ratio compared with base fluid. Additionally, the $\mathrm{SiO}_{2}$-water nanofluid was rated best since it achieved the highest enhancement ratio among different kinds of nanofluid followed by aluminum oxide, zinc oxide, and copper oxide water nanofluids for reasons explained previously. 

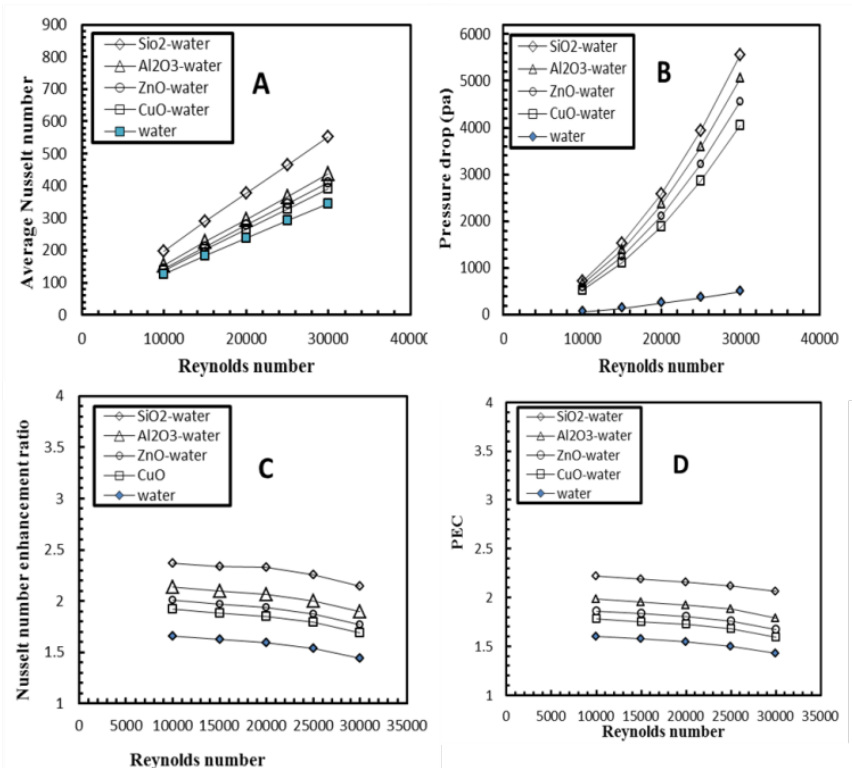

Figure 5. The impact of various types of nanofluids of semicircle zigzag- corrugated channel on (A) $\mathrm{Nu},(\mathrm{B}) \Delta \mathrm{p},(\mathrm{C})$ $\mathrm{Nu}_{\mathrm{er}}$, and (D) PEC

Figure 5 (D) delineates the influence of each type of nanofluid on PEC. Each type of nanofluid gives higher performance factor compared with base fluid. While it is true that nanofluid with silicon dioxide particles displays the highest magnitude of the $\Delta p$, it recorded the largest enhancement in heat transfer. As a result, with 2.22 at $\mathrm{Re}=10000$ nanofluid with silicon dioxide nanoparticles offered the maximum value of PEC among the other kinds of nanofluids.

\subsection{Nanoparticles volume fraction effect}

Figure 6 plotted the velocity and isotherms contours for different solid volume fraction of nanofluid with silicon dioxide nanoparticles at $\mathrm{Re}=30000 \mathrm{dp}=20 \mathrm{~nm}$. The figure gives a decent image of the progress of the flow as well as the converse flow of fluid and increase in recirculation zones due to increase in the $\phi$. The recirculation zones seemed linked to the highest $\phi$, and in this way, the irregular motion of nanoparticles will increment and therefore increment the intensity of recirculation zones. This is compatible and consistent with the studies of Ahmed et al. [28] and Mohammed et al. [1].

The temperature contours demonstrate the effect of corrugated surface alongside with volume fraction on the temperature gradient near the corrugated walls due to enhancement in the working fluid via mixing the converse flow which is in contact with channel walls with the main flow in the center of channel. Additionally, increasing $\phi$ leads to increase the irregular motions of nanoparticles which inferred to enhanced heat transfer and the rates of energy exchange.

The $\mathrm{Nu}_{\mathrm{av}}$ against $\mathrm{Re}$ with various types of volume fractions is displayed in Figure7 (A). As predicted, the $\mathrm{Nu}_{\mathrm{av}}$ rises in tandem with $\mathrm{Re}$ increases, depending on volume fraction. In other words, it is clear there was a significant effect of nanoparticles volume fraction to jack up the $\mathrm{Nu}$ rate at a certain Re. Regarding the nanoparticles, the Brownian motion and strong improvement of thermal conductivity could explain the increase of the $\mathrm{Nu}_{\mathrm{av}}$

(a)
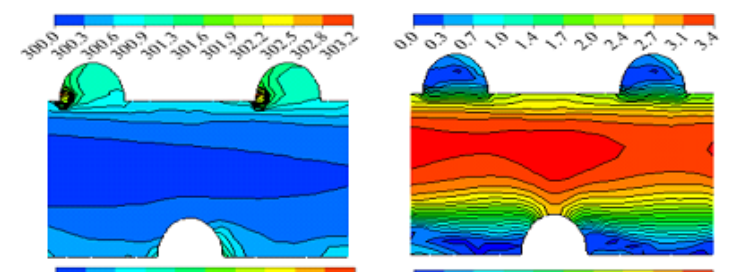

(b)
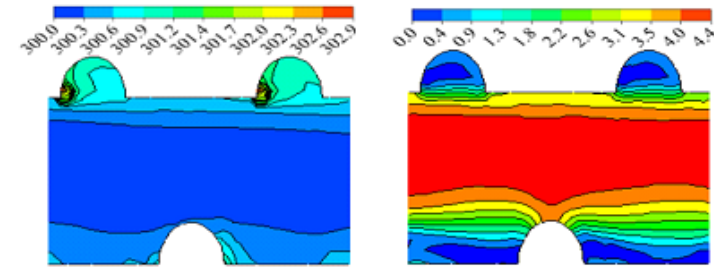

(c)
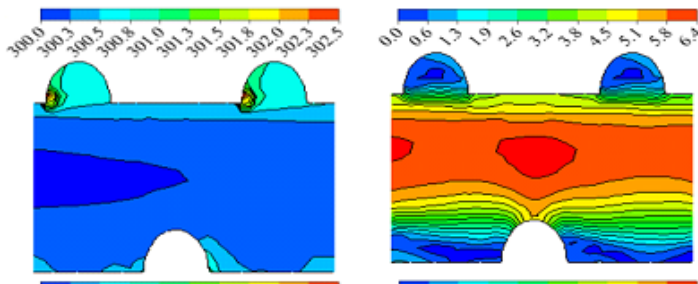

(d)
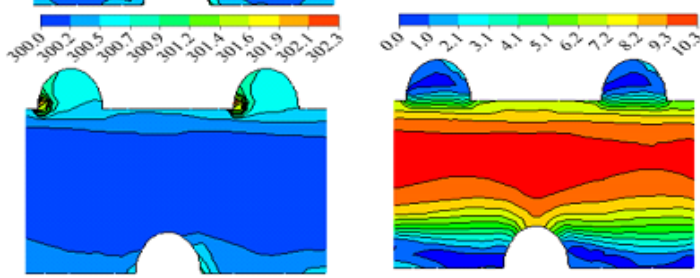

Figure 6. Streamlines (right) and isotherms (left) contours of $\mathrm{SiO}_{2}$-water for different nanoparticles volume fraction at $\mathrm{Re}=30000$ : (a) 0.02, (b) 0.04, (c) 0.06, and (d) 0.08

Figure 7(B) indicates the style of pressure drop against Re with numerous solid volume fractions of nanofluid with silicon dioxide nanoparticles. The most striking finding was that the pressure drop has been significantly boosted with the raising of $\phi$ as well as Re. To understand why, we should be first look at the properties of nanofluid, specifically viscosity, where high volume fraction means high viscosity, and the high velocity gradient of mixing at the walls of channel which is associated with the re-circulation flow of corrugated channel. Abed et al. [24] and Mohammed et al. [1] previously found comparable outcomes.

The obtained results of the enhancement in $\mathrm{Nu}$ ratio of silicon dioxide -water nanofluid with various volume fractions are elaborated in Figure 7(C). Although there were falls in tandem with increase in Re in terms of enhancement ratio for all volume fractions of the fluids, the nanofluid types recorded the highest enhancement ratio compared with base fluid. Plainly, the $\mathrm{SiO}_{2}$-water nanofluid with $8 \%$ volume fraction offered highest enhancement ratio compared with the others. This is because of the higher thermal conductivity and viscosity for the heat transfer medium, which leads to improve the converse flow near by the corrugated walls.

Figure 7(D) demonstrates the variation of PEC against Re with various solid volume fractions of nanofluid with silicon dioxide nanoparticles. Evidently, the values of PEC of nanofluids at different volume fraction over Reynolds number range were greater than base fluid. This is because thermal performance factor depends on the heat transfer enhancement which can be deduced from enhanced $\mathrm{Nu}$ results. Also, the results indicated that PEC fell in tandem 
with increasing Reynolds number for all types of fluid. In other words, this means the heat gained or heat transfer enhancement is much less than pressure loss. However, nanofluid with silicon dioxide nanoparticles at $8.0 \%$ volume fraction gives the best PEC recorded at 2.22 at $\mathrm{Re}=10000$.
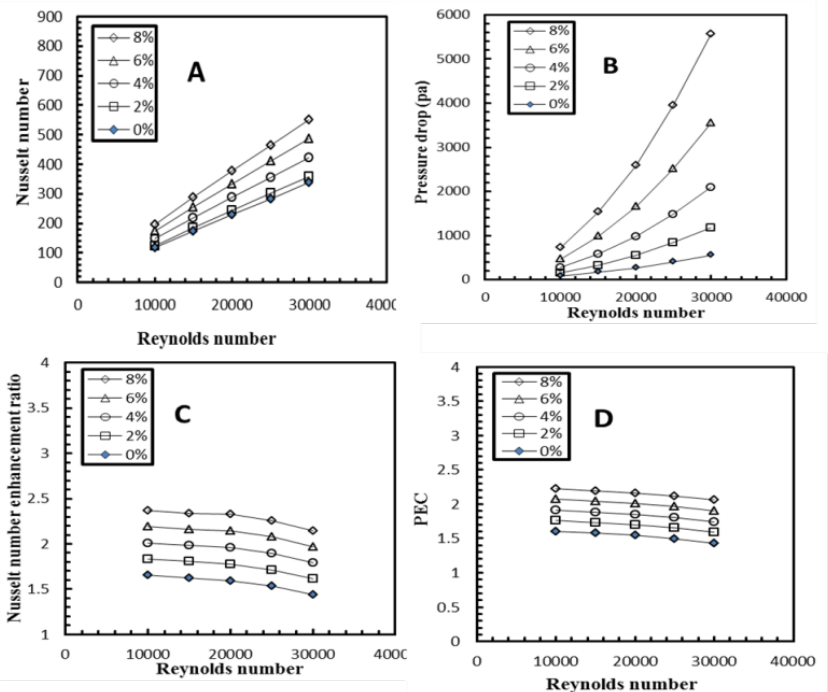

Figure 7. The effect of nanoparticles volume fraction of $\mathrm{SiO}_{2}$ on (A) Nu number, (B) $\Delta \mathrm{p}$, (C) $N u_{e r}$ number, and (D) PEC

\subsection{Nanoparticles diameter effect}

For a better comprehension of the flow and heat transfer characteristics, the velocity and isotherm contours for various nanoparticle diameter of silicon dioxide at $\mathrm{Re}=30000$ and $\phi$ $=8 \%$ are shown in Figure 8 . The figure gives a decent image of the progress of the flow as well as the reverse flow of fluid and increase recirculation zones due to decrease in the diameter of nanoparticles. The recirculation zones seemed linked to the lowest diameter of nanoparticles. As previously stated, the irregular motions of nanoparticles will increment and therefore increment the intensity of recirculation zones. Abed et al. [24] obtained the same result.

From temperature contours, the effect of corrugated surface can be seen alongside with decrease in the diameter of nanoparticles on the temperature gradient near the top and bottom walls due to enhancement of the working fluid via mixing the reserve flow, which is in contact with channel walls with the main flow in the center of channel. Additionally, decrease in nanoparticle diameter leads to increase the irregular motions of nanoparticles, which infer enhanced heat transfer and the rates of energy exchange. $\mathrm{SiO}_{2}$-water nanofluid at volume fraction $8 \%$ has been utilized to examine the impact of silicon dioxide diameter on $\mathrm{Nu}_{\mathrm{av}}$ under nanoparticles diameter range of $20-80 \mathrm{~nm}$. As shown in Figure $9(\mathrm{~A})$, the $\mathrm{Nu}_{\mathrm{av}}$ rose in tandem with decreasing diameter of nanoparticle and increasing of Re. The major cause of this increase is the strength of Brownian motion that has a great influence on thermal conductivity and enhances it. The other reason is increase in the specific area due to decrease in nanoparticle diameter. Therefore, the thermal conductivity increases not only by Brownian motion, but also by increase in the specific area and this mechanism was adduced in a previous study by Mohammed et al. [1] and Abed et al. [24]. (a)

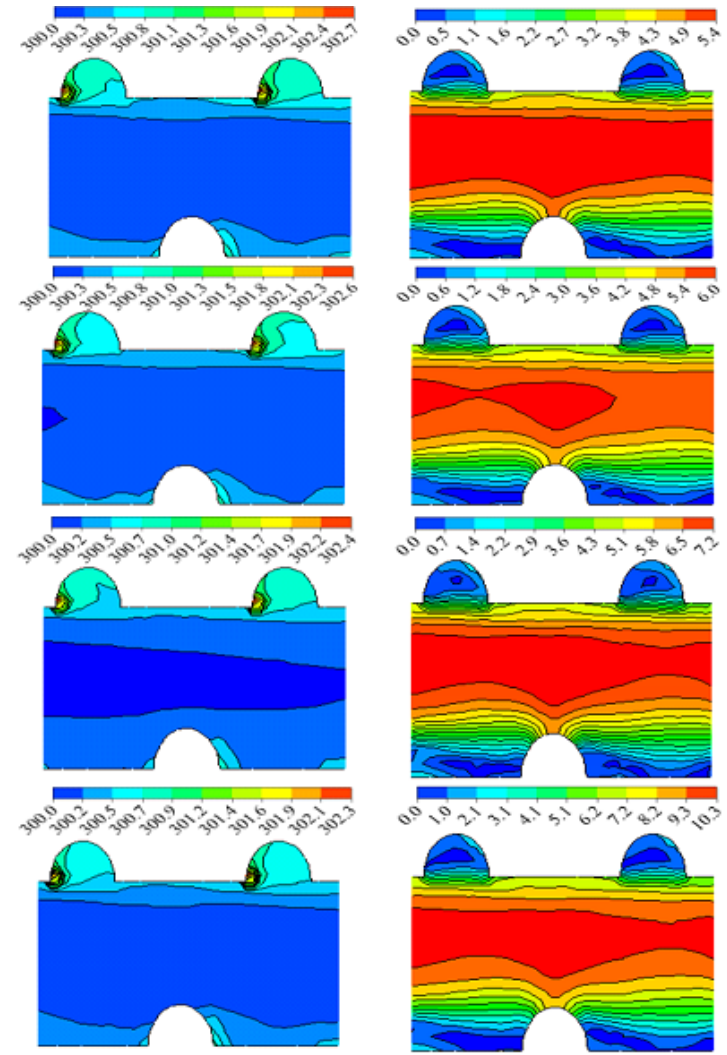

Figure 8. Streamlines (right) and isotherms (left) contours of $\mathrm{SiO}_{2}$-water for different nanoparticles diameter at $\mathrm{Re}=30000$ : (a) $80 \mathrm{~nm}$, (b) $60 \mathrm{~nm}$, (c) $40 \mathrm{~nm}$, and (d) $20 \mathrm{~nm}$

Figure 9(B) displayed the impact of particle diameter for nanofluid with silicon dioxide nanoparticles on the pressure drop at $\phi=8 \%$ and different Reynolds number. As shown, as the diameter of nanoparticle decreases, the $\Delta p$ increases due to the rise in viscosity of nanofluids, which is the same result obtained by Abed et al. [24], in addition to the effect of reverse flow zone, which is smaller in cases of large diameter than small diameter. This implies that the strength of reverse flow will increase and cause more friction between the nanofluid and corrugated walls, leading to increase in the $\Delta p$ penalty.

Figure $9(\mathrm{C})$ illustrated the obtained results of the $\mathrm{Nu}_{\mathrm{er}}$ of $\mathrm{SiO}_{2}$-water nanofluid with various diameter of nanoparticle in the semicircle zigzag-corrugated channel to that for the base fluid in flat channel. Although there were falls in tandem with increases Reynolds number in the enhancement ratio for all diameter of the nanoparticles, the nanofluid types recorded the highest enhancement ratio compared with base fluid. Due to the influence of higher viscosity and thermal conductivity, the $\mathrm{SiO}_{2}$-water nanofluid with $20 \mathrm{~nm}$ diameter offered highest enhancement ratio compared with the others.

Thermal performance factor of semicircle zigzagcorrugated channel at volume fraction $8 \%$ and under different range of Reynolds number was accomplished and displayed in Figure 9 (D). Evidently, the values of PEC of nanofluids at various diameters of nanoparticles over Reynolds number range were greater than pure water. As mentioned earlier, this is because thermal performance factor depends on the heat transfer enhancement which can be deduced from enhanced $\mathrm{Nu}$ results. Also, the results indicated that PEC fell in tandem with increasing Re for all types of fluid. In other words, this means the pressure loss is much greater than heat gained or heat transfer enhancement. However, $\mathrm{SiO}_{2}-$ water 
nanofluid with $20 \mathrm{~nm}$ diameter gives the best PEC, recorded at 2.22 at $\mathrm{Re}=10000$.
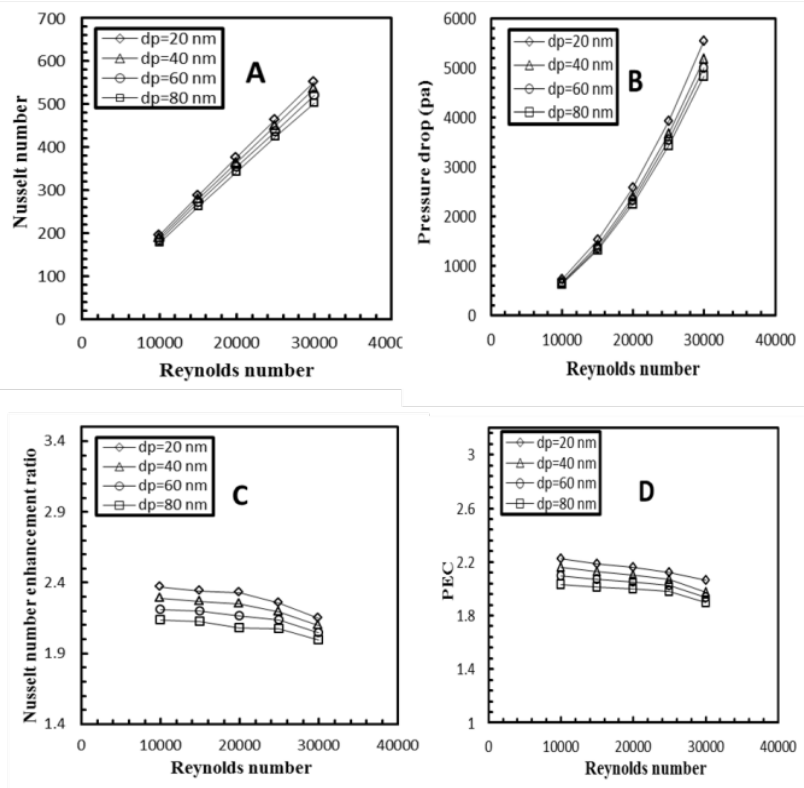

Figure 9. The effect of nanoparticle diameter of $\mathrm{SiO}_{2}$ on (A) $\mathrm{Nu},(\mathrm{B}) \Delta \mathrm{p}$, (C) $\mathrm{Nu}_{\mathrm{er}}$, and (D) PEC

\subsection{Effect of different Reynolds number}

Figure 10 illustrated the axial velocity contours for nanofluid with silicon dioxide nanoparticles flow in the test channel at $8 \%$ solid volume fraction and $\mathrm{dp}=20 \mathrm{~nm}$ for different Re. The re-circulation zones before and after the corrugation for the lower corrugated wall are presented clearly from these contour plots. Generally, for all cases, the recirculation zones between corrugations also affect the local thermal enhancement. In addition, the considerable difference in reverse flow pattern at different Reynolds number is clear.

In addition, an increase in Re leads to decrease the recirculation zone before the corrugation, while the recirculation zone after the corrugation expands. This seems related to the effect of increasing velocity which depends on the Reynolds number. Furthermore, the largest recirculation zone is after the corrugation, which corresponds to the zone with the highest value of local Nusselt number.

Figure 11 illustrated the obtained results of the local $\mathrm{Nu}$ with x-position for various $\mathrm{Re}$ of $\mathrm{SiO}_{2}$-water nanofluid at $\phi=8 \%, \mathrm{dp}=20 \mathrm{~nm}$ in the semicircle zigzag-corrugated channel. Evidently, it can be noted that as the Re rises, the local $\mathrm{Nu}$ increases. The nanofluid with higher Re can lead to develop the fluids mixing as well as generation of smaller fluctuation scales which improve the heat transfer and reduce thermal boundary layer thickness. Hence, the $\mathrm{Re}=30000$ produced the highest heat transfer enhancement over other values of Re.

\section{CONCLUSION}

In this paper, turbulent forced convective of nanofluids with nanoparticles of silicon dioxide, aluminum oxide, zinc oxide, and copper oxide flowing in a semicircle zigzagcorrugated channels over $\mathrm{Re}$ in the range of $10,000 \leq \mathrm{Re}$ $\leq 30,000$ are numerically conducted. Regarding the nanofluid, the impact of different values of nanoparticle volume fractions with ranges of $0-8 \%$ and nanoparticle diameters with ranges of 20-80 $\mathrm{nm}$ was discussed. The major conclusion of this numerical study is that the utilization of nanofluid in corrugated channels can be offered as an appropriate way to get best thermal performance, which can prompt design plan of heat exchangers and make it more compact. Other conclusions that can be drawn from the current study include:

1) The corrugation profile of semicircle zigzag corrugated channel had a great impact on the thermal performance compared with straight profile.

2) The adopted geometry of semicircle corrugated channel can progress heat transfer enhancement at the rate of 1.5-2.7 times that of straight channel.

3) For all channel shapes, the $\mathrm{Nu}_{\mathrm{av}}$ and $\Delta \mathrm{p}$ increases with increasing $\phi$ and $\operatorname{Re}$ and decreases with decreasing nanoparticle diameter.

4) The PEC was consistent with the $\mathrm{Nu}_{\mathrm{av}}$ and $\Delta \mathrm{p}$ with respect to the effect of $\phi$, but Re had the opposite effect as PEC decreased when the Re increased.

5) Among the four types of nanopowder which are tested, silicon dioxide - water recorded the best heat transfer enhancement followed by aluminum oxide, zinc oxide, and copper oxide -water nanofluids.

6) Over the range investigated $(\mathrm{Re}=10000-30000)$, the zigzag shape of semicircle corrugated channel achieved the maximum PEC of 2.22 at volume fraction 0.08 and $\mathrm{Re}=10000$.
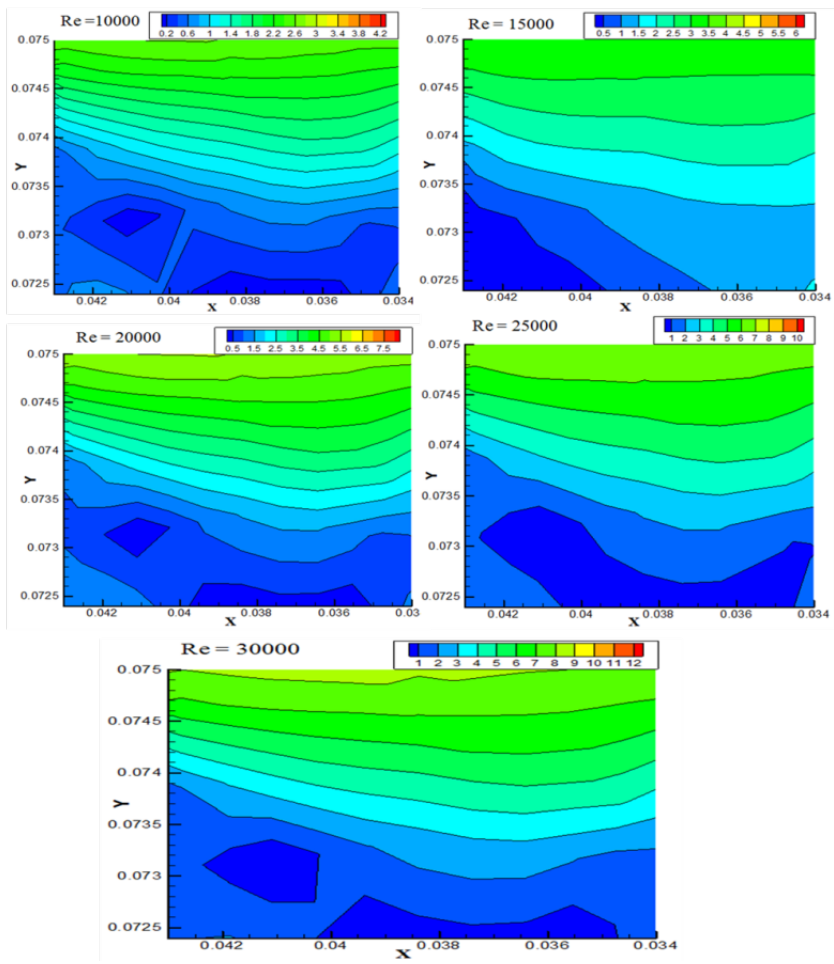

Figure 10. Effect of Reynolds number on size of recirculation zone of $\mathrm{SiO}_{2}$-water nanofluid 


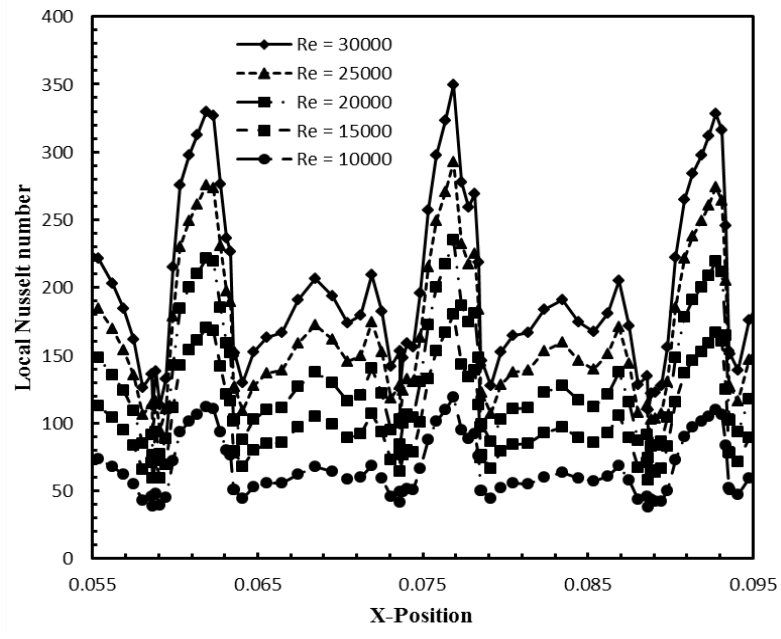

Figure 11. Local Nusselt number with x-position for different Reynolds number

\section{ACKNOWLEDGMENT}

The authors wish to acknowledge that this paper and the work was funded by the Fundamental Research Grant Scheme (FRGS 1589), University Tun Hussein Onn Malaysia.

\section{REFERENCES}

[1] Mohammed HA, Al-Shamani AN, Sheriff JM. (2012). Thermal and hydraulic characteristics of turbulent nanofluids flow in a rib-groove channel. International Communications in Heat and Mass Transfer 39(10): 1584-94.

https://doi.org/10.1016/j.icheatmasstransfer.2012.10.02 0 .

[2] Togun H, Ahmadi G, Abdulrazzaq T, Shkarah AJ, Kazi SN, Badarudin A, Safaei MR. (2015). Thermal performance of nanofluid in ducts with double forwardfacing steps. Journal of the Taiwan Institute of Chemical Engineers 47: 28-42. https://doi.org/10.1016/j.jtice.2014.10.009

[3] El-Maghlany WM, Elazm MM, Shehata AI, Teamah MA. (2016). A novel technique for heat transfer enhancement from a horizontal heated pipe by using nanofluid restrained flow. Journal of the Taiwan Institute of Chemical Engineers 68: 338-50. https://doi.org/10.1016/j.jtice.2016.09.024

[4] Arani AA, Amani J. (2013). Experimental investigation of diameter effect on heat transfer performance and pressure drop of $\mathrm{TiO}_{2}$-water nanofluid. Experimental Thermal and Fluid Science 44: 520-33. https://doi.org/10.1016/j.expthermflusci.2012.08.014

[5] Bianco V, Manca O, Nardini S. (2011). Numerical investigation on nanofluids turbulent convection heat transfer inside a circular tube. International Journal of Thermal Sciences 50(3): 341-9. https://doi.org/10.1016/j.ijthermalsci.2010.03.008

[6] Fabbri G. (2000). Heat transfer optimization in corrugated wall channels. International Journal of Heat and Mass Transfer 43(23): 4299-310. https://doi.org/10.1016/S0017-9310(00)00054-5

[7] Bahaidarah HM, Anand NK, Chen HC. (2005).
Numerical study of heat and momentum transfer in channels with wavy walls. Numerical Heat Transfer, Part A 47(5): 417-39. https://doi.org/10.1080/10407780590891218

[8] Amiri EO. (2018). Application of computational experiments based on the response surface methodology for studying of the recirculation zone in the Y-shaped channe. Mathematical Modelling of Engineering Problems 5(3): 243-248. https://doi.org/10.18280/mmep.050317

[9] Naphon P. (2007). Laminar convective heat transfer and pressure drop in the corrugated channels. International Communications in Heat and Mass Transfer 34(1): 6271. https://doi.org/10.1016/j.icheatmasstransfer.2006.09.00 3

[10] Naphon P. (2008). Effect of corrugated plates in an inphase arrangement on the heat transfer and flow developments. International Journal of Heat and Mass Transfer 51(15-16): 3963-71. https://doi.org/10.1016/j.ijheatmasstransfer.2007.11.050

[11] Naphon P. (2009). Effect of wavy plate geometry configurations on the temperature and flow distributions. International Communications in Heat and Mass Transfer 36(9): 942-6. https://doi.org/10.1016/j.icheatmasstransfer.2009.05.00 7

[12] Mohamed N, Khedidja B, Abdelkader S, Belkacem Z. (2007). Heat transfer and flow field in the entrance region of a symmetric wavy-channel with constant wall heat flux density. Int. J. Dyn. Fluid 3(1): 63-79.

[13] Elshafei EA, Awad MM, El-Negiry E, Ali AG. (2010). Heat transfer and pressure drop in corrugated channels. Energy 35(1): 101-10. https://doi.org/10.1016/j.energy.2009.08.031

[14] Islamoglu Y, Parmaksizoglu C. (2003). The effect of channel height on the enhanced heat transfer characteristics in a corrugated heat exchanger channel. Applied Thermal Engineering 23(8): 979-87. https://doi.org/10.1016/S1359-4311(03)00029-2

[15] Ali MM, Ramadhyani S. (1992). Experiments on convective heat transfer in corrugated channels. Experimental Heat Transfers an International Journal 5(3): 175-93. https://doi.org/10.1080/08916159208946440

[16] Hong ZC, Zhen CE, Yang CY. (2008). Fluid dynamics and heat transfer analysis of three dimensional microchannel flows with microstructures. Numerical Heat Transfer, Part A: Applications 54(3): 293-314. https://doi.org/10.1080/10407780701790128

[17] Zhang L, Che D. (2011). Influence of corrugation profile on the thermal hydraulic performance of crosscorrugated plates. Numerical Heat Transfer, Part A: Applications 59(4): 267-96. https://doi.org/10.1080/10407782.2011.540963

[18] Yutaka A, Hiroshi N, Faghri M. (1988). Heat transfer and pressure drop characteristics in a corrugated duct with rounded corners. International Journal of Heat and Mass $\quad$ Transfer $31(6)$ : 1237-45. https://doi.org/10.1016/0017-9310(88)90066-X

[19] Mohammed HA, Bhaskaran G, Shuaib NH, AbuMulaweh HI. (2011). Influence of nanofluids on parallel flow square microchannel heat exchanger performance. International Communications in Heat and Mass 
[20] Abu-Nada E. (2008). Application of nanofluids for heat transfer enhancement of separated flows encountered in a backward facing step. International Journal of Heat and Fluid Flow 29(1): 242-9. https://doi.org/10.1016/j.ijheatfluidflow.2007.07.001

[21] Santra AK, Sen S, Chakraborty N. (2009). Study of heat transfer due to laminar flow of copper-water nanofluid through two isothermally heated parallel plates. International Journal of Thermal Sciences 48(2): 391400. https://doi.org/10.1016/j.ijthermalsci.2008.10.004

[22] Kalteh M, Abbassi A, Saffar-Avval M, Harting J. (2011). Eulerian-Eulerian two-phase numerical simulation of nanofluid laminar forced convection in a microchannel. International Journal of Heat and Fluid Flow 32(1): 107-16. https://doi.org/10.1016/j.ijheatfluidflow.2010.08.001

[23] Ajeel RK, Salim WS. (2017). A CFD study on turbulent forced convection flow of $\mathrm{Al}_{2} \mathrm{O}_{3}$-water nanofluid in semi-circular corrugated channel. InIOP Conference Series: Materials Science and Engineering 243(1): 012020. https://doi.org/10.1088/1757899X/243/1/012020

[24] Abed AM, Sopian K, Mohammed HA, Alghoul MA, Ruslan MH, Mat S, Al-Shamani AN. (2015). Enhance heat transfer in the channel with V-shaped wavy lower plate using liquid nanofluids. Case Studies in Thermal Engineering 5: 13-23. https://doi.org/10.1016/j.csite.2014.11.001

[25] Ahmed MA, Yusoff MZ, Ng KC, Shuaib NH. (2015). Numerical investigations on the turbulent forced convection of nanofluids flow in a triangular-corrugated channel. Case Studies in Thermal Engineering 6: 21225. https://doi.org/10.1016/j.csite.2015.10.002

[26] Schlichting H, Gersten K, Krause E, Oertel HJ, Mayes C. (2000). Boundary Layer Theory Springer. Eigth Revised and Enlarged Edition.

[27] Launder BE, Sharma BI. Application of the energydissipation model of turbulence to the calculation of flow near a spinning disc. Letters in heat and mass transfer. 1974 Nov 1; 1(2):131-7.

[28] Mohammed HA, Abed AM, Wahid MA. (2013). The effects of geometrical parameters of a corrugated channel with in out-of-phase arrangement. International Communications in Heat and Mass Transfer 40: 47-57. https://doi.org/10.1016/j.icheatmasstransfer.2012.10.02 2

[29] Ahmed MA, Shuaib NH, Yusoff MZ, Al-Falahi AH. (2011). Numerical investigations of flow and heat transfer enhancement in a corrugated channel using nanofluid. International Communications in Heat and Mass Transfer 38(10): 1368-75. https://doi.org/10.1016/j.icheatmasstransfer.2011.08.01 3

[30] Manca O, Nardini S, Ricci D. (2012). A numerical study of nanofluid forced convection in ribbed channels. Applied Thermal Engineering 37: 280-92. https://doi.org/10.1016/j.applthermaleng.2011.11.030

[31] Vajjha RS, Das DK, Kulkarni DP. (2010). Development of new correlations for convective heat transfer and friction factor in turbulent regime for nanofluids. International Journal of Heat and Mass Transfer 53(21-

22):

4607-18.

https://doi.org/10.1016/j.ijheatmasstransfer.2010.06.032

[32] Koo J, Kleinstreuer C. (2005). Impact analysis of nanoparticle motion mechanisms on the thermal conductivity of nanofluids. International Communications in Heat and Mass Transfer 32(9): 1111-8.

https://doi.org/10.1016/j.icheatmasstransfer.2005.05.01 4

[33] Incropera FP, DeWitt DP, Bergman TL, Lavine AS. (2006). Fundamentals of Heat and Mass Transfer, 6th edn.

[34] Gnielinski V. (1976). New equations for heat and mass transfer in turbulent pipe and channel flow. Int. Chem. Eng. 16(2): 359-68.

[35] Petukhov BS. (1970). Heat transfer and friction in turbulent pipe flow with variable physical properties. In Advances in Heat Transfer 6: 503-564. https://doi.org/10.1016/S0065-2717(08)70153-9

\section{NOMENCLATURE}

\begin{tabular}{ll}
$\mathrm{B}$ & area, mm ${ }^{2}$ \\
$\mathrm{Al}_{2} \mathrm{O}_{3}$ & aluminum oxide \\
$C_{\mu}$ & turbulent model constant \\
$\mathrm{C}_{\varepsilon}$ & turbulent model constant \\
$\mathrm{CuO}$ & copper oxide \\
$\mathrm{Cp}$ & specific heat capacity, $(\mathrm{J} / \mathrm{kg} . \mathrm{K})$ \\
$\mathrm{C}_{f}$ & skin friction coefficient \\
$D_{h}$ & hydraulic diameter, mm \\
$d_{p}$ & diameter of nanofluid particles, nm \\
$d_{f}$ & equivalent diameter of a base fluid \\
& molecule, $\mu \mathrm{m}$ \\
$\mathrm{G}$ & generation of turbulent kinetic energy, \\
& (kg/ms ${ }^{3}$ ) \\
$\mathrm{h}$ & corrugated height, mm \\
$\mathrm{k}$ & thermal conductivity, $\mathrm{W} / \mathrm{m} . \mathrm{K}$ \\
$\mathrm{H}$ & height of channel, mm \\
$I$ & turbulent intensity \\
\hline $\mathrm{Nu}$ & average Nusselt number \\
$p$ & pressure, N/m ${ }^{2}$ \\
$\mathrm{Pr}$ & Prandtl number \\
$\Delta \mathrm{p}$ & pressure drop, $(\mathrm{pa})$ \\
$\mathrm{Re}$ & Reynolds number \\
$T$ & temperature, $\mathrm{K}$ \\
$u, v$ & velocity components, $\mathrm{m} / \mathrm{s}$ \\
$x, y$ & horizontal and vertical coordinates, $\mathrm{m}$ \\
$\mathrm{SiO}{ }_{2}$ & silicon dioxide \\
$\mathrm{ZnO}$ & zinc oxide \\
&
\end{tabular}

\section{Greek symbols}

$\begin{array}{cl}\rho & \text { density, } \mathrm{kg} / \mathrm{m}^{3} \\ \mu & \text { dynamic viscosity, } \mathrm{kg} / \mathrm{m} . \mathrm{s} \\ \mu_{t} & \text { turbulent viscosity } \\ \sigma_{k} & \text { diffusion Prandtl number for } \mathrm{k} \\ \varepsilon & \text { turbulent dissipation, } \mathrm{m}^{2} / \mathrm{s}^{3} \\ \phi & \text { Nanoparticle volume fraction }\end{array}$

\section{Subscripts}

o 
